Article

\title{
Synthesis, Crystal Structure and Luminescent Property of Cd (II) Complex with $N$-Benzenesulphonyl- $L$-leucine
}

\author{
Xishi Tai * and Jinhe Jiang \\ College of Chemistry and Chemical Engineering, Weifang University, Weifang 261061, China; \\ E-Mail: jiangjinhe2006@163.com (J.H.) \\ * Author to whom correspondence should be addressed; E-Mail: taixs@wfu.edu.cn; \\ Tel.: +86-536-8785363; Fax: +86-536-8785363.
}

Received: 13 July 2012; in revised form: 3 August 2012 / Accepted: 7 September 2012 / Published: 14 September 2012

Abstract: A new trinuclear $\mathrm{Cd} \quad$ (II) complex $\quad\left[\mathrm{Cd}_{3}(\mathrm{~L})_{6}(2,2 \text {-bipyridine })_{3}\right]$ $[\mathrm{L}=N$-phenylsulfonyl- $L$-leucinato $]$ has been synthesized and characterized by elemental analysis, IR and X-ray single crystal diffraction analysis. The results show that the complex belongs to the orthorhombic, space group $P 22_{1} 2_{1} 2_{1}$ with $a=16.877(3) \AA, b=22.875(5) \AA$, $c=29.495(6) \AA, \alpha=\beta=\gamma=90^{\circ}, V=11387(4) \AA^{3}, Z=4, D_{c}=1.416 \mu \mathrm{g} \cdot \mathrm{m}^{-3}$, $\mu=0.737 \mathrm{~mm}^{-1}, F(000)=4992$, and final $R_{1}=0.0390, \omega R_{2}=0.0989$. The complex comprises two seven-coordinated $\mathrm{Cd}$ (II) atoms, with a $\mathrm{N}_{2} \mathrm{O}_{5}$ distorted pengonal bipyramidal coordination environment and a six-coordinated $\mathrm{Cd}$ (II) atom, with a $\mathrm{N}_{2} \mathrm{O}_{4}$ distorted octahedral coordination environment. The molecules form one dimensional chain structure by the interaction of bridged carboxylato groups, hydrogen bonds and $\pi-\pi$ interaction of 2,2-bipyridine. The luminescent properties of the $\mathrm{Cd}$ (II) complex and $\mathrm{N}$-Benzenesulphonyl- $\mathrm{L}$-leucine in solid and in $\mathrm{CH}_{3} \mathrm{OH}$ solution also have been investigated.

Keywords: $N$-Benzenesulphonyl- $L$-leucine; trinuclear Cd (II) complex; synthesis; crystal structure; luminescent property

\section{Introduction}

Investigation of the inorganic-organic hybrid materials with carboxylate ligands has gained considerable attention during the last decade due to their attractive structures and promising potential applications for catalysis, gas storage, magnetic, luminescence materials [1-7]. Structural studies have 
shown that the organic ligands containing multi-oxygen and nitrogen atoms can coordinate with metal ions in different ways, resulting in the formation of various metal-organic frameworks with specific topologies and useful properties. The Cd (II) complexes have gained considerable attention due to their luminescent properties [4]. We have been exploring the preparation of inorganic-organic hybrid materials by combining metal ions and organic ligands containing multi-oxygen and nitrogen atoms. We have now synthesized a new hybrid material, $\left[\mathrm{Cd}_{3}(\mathrm{~L})_{6}(2,2 \text {-bipyridine })_{3}\right][\mathrm{L}=N$-phenylsulfonyl- $L$-leucinato $]$. The luminescent properties of the $\mathrm{Cd}$ (II) complex and $N$-Benzenesulphonyl- $L$-leucine in solid and in $\mathrm{CH}_{3} \mathrm{OH}$ solution also have been investigated.

\section{Results and Discussion}

\subsection{IR Spectra}

The $v_{\text {as }}(\mathrm{COOH}), v_{\mathrm{s}}(\mathrm{COOH})$ and $v(\mathrm{C}=\mathrm{N})$ vibrations of free ligand are at $1,659 \mathrm{~cm}^{-1}$ and $1,436 \mathrm{~cm}^{-1}$ and $1587 \mathrm{~cm}^{-1}$, respectively. For the Cd (II) complex, they shift to $1,587 \mathrm{~cm}^{-1}, 1,402 \mathrm{~cm}^{-1}$ and $1552 \mathrm{~cm}^{-1}$, respectively, which suggest that the oxygen atoms of $\mathrm{COO}^{-}$and the nitrogen atoms of 2,2-bipyridine coordinate to $\mathrm{Cd}$ (II) ions [8]. The difference between the $v_{\mathrm{as}}\left(\mathrm{COO}^{-}\right)$and $v_{\mathrm{s}}\left(\mathrm{COO}^{-}\right)$ band is $185 \mathrm{~cm}^{-1}$, indicating a bidentate carboxylate moiety, consistent with the X-ray structural analysis. The new band at $419 \mathrm{~cm}^{-1}$ is assigned to the $v(\mathrm{Cd}-\mathrm{O})$ vibration.

\subsection{Structure Description}

The molecular structure and molecular packing arrangement are shown in Figures 1 and 2, respectively. Figure 3 shows the coordination environment of the $\mathrm{Cd}$ (II) atom. From Figures 1 and 3, we can see that two coordination environments of the $\mathrm{Cd}$ (II) atoms exist in the complex. The first coordination environment of the $\mathrm{Cd}$ (II) atom [Cd1, Cd3] is a distorted pengonal bipyramidal coordination environment with five oxygen atoms from the $N$-phenylsulfonyl- $L$-leucinato ligand, two nitrogen atoms from 2,2-bipyridine. The second coordination environment of the $\mathrm{Cd}$ (II) atom [Cd2] is a distorted octahedral coordination environment with four oxygen atoms from the $N$-phenylsulfonyl- $L$-leucinato ligand, two nitrogen atoms from 2,2-bipyridine. The carboxylates have three coordination ways of in the Cd (II) complex (Figure 4). The distances of the $\mathrm{Cd}-\mathrm{O}$ bonds and $\mathrm{Cd}-\mathrm{N}$ bonds are in the range of 2.244(3)-2.450(4) $\AA$ and 2.329(4)-2.366(4) $\AA$, respectively. The aromatic rings of 2,2-bipyridine in the complex are nearly parallel, the dihedral angle and distance between ring 1 (containing N71 and $\mathrm{N} 72$ ) and ring 2 (containing N81 and N82) are $7.8(3)^{\circ}$ and 3.846(4) $\AA$, ring 2 (containing N81 and N82) and ring 3 (containing N91 and N92) are 6.2(3) and 3.886(4) $\AA$. The hydrogen bonds and $\pi-\pi$ interaction of 2,2-bipyridine rings help to stabilize the structure. The bond lengths of Cd-O are similar to the $\mathrm{Cd}-\mathrm{O}$ bond lengths reported previously $[9,10]$. The aromatic rings in the molecules do not show any unusual features, and the bond lengths and bond angles are within the range of normal values. 
Figure 1. The molecular structure of the Cd (II) complex.

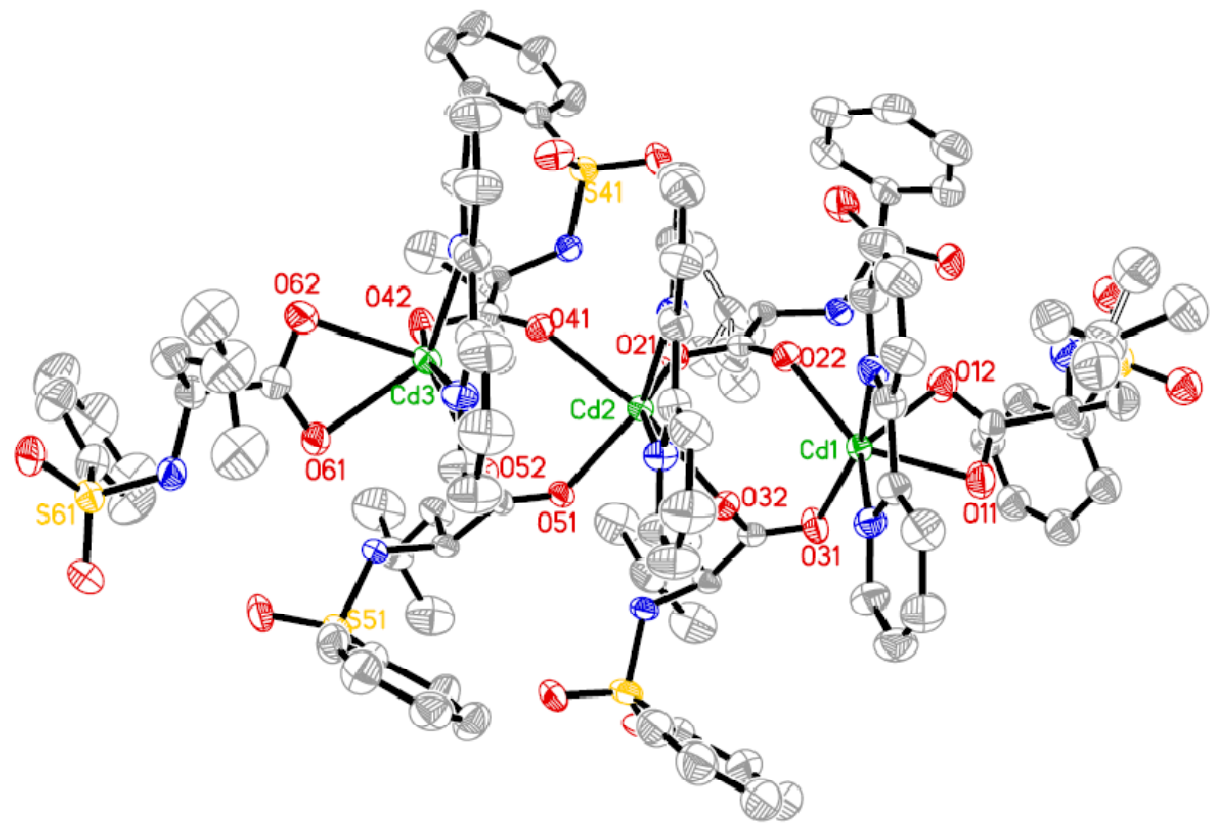

Figure 2. The molecular packing arrangement of the Cd (II) complex.

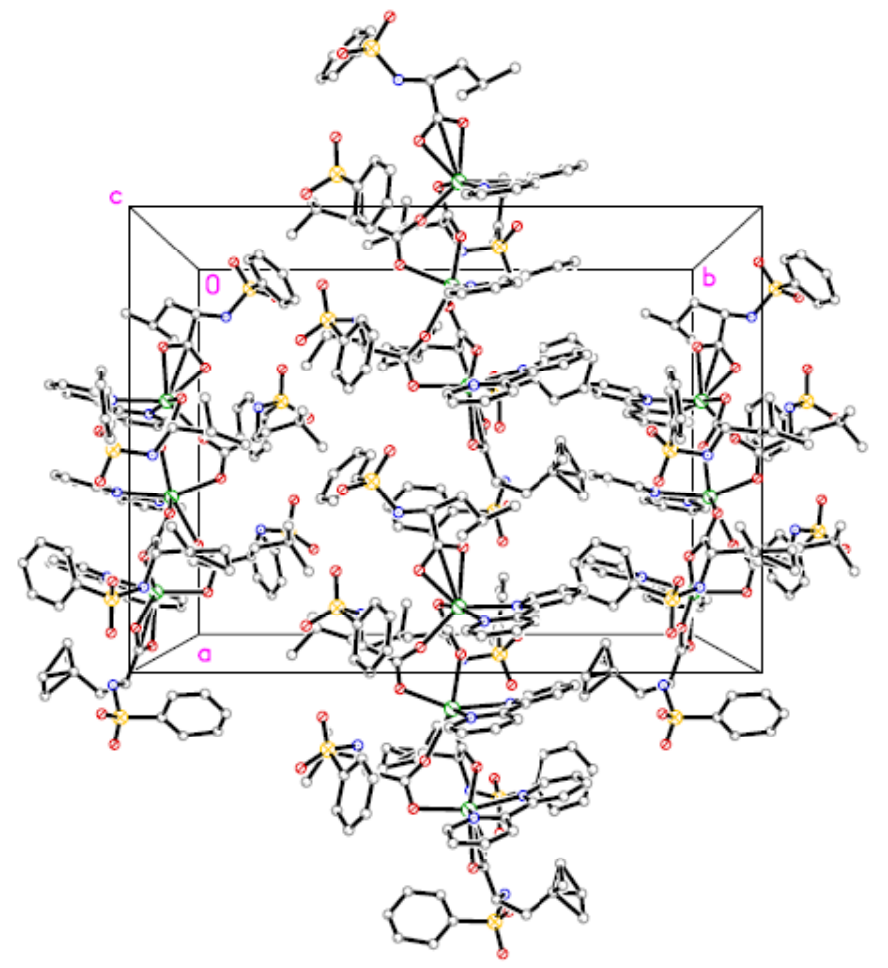


Figure 3. The coordination environment of the $\mathrm{Cd}$ (II) ions.

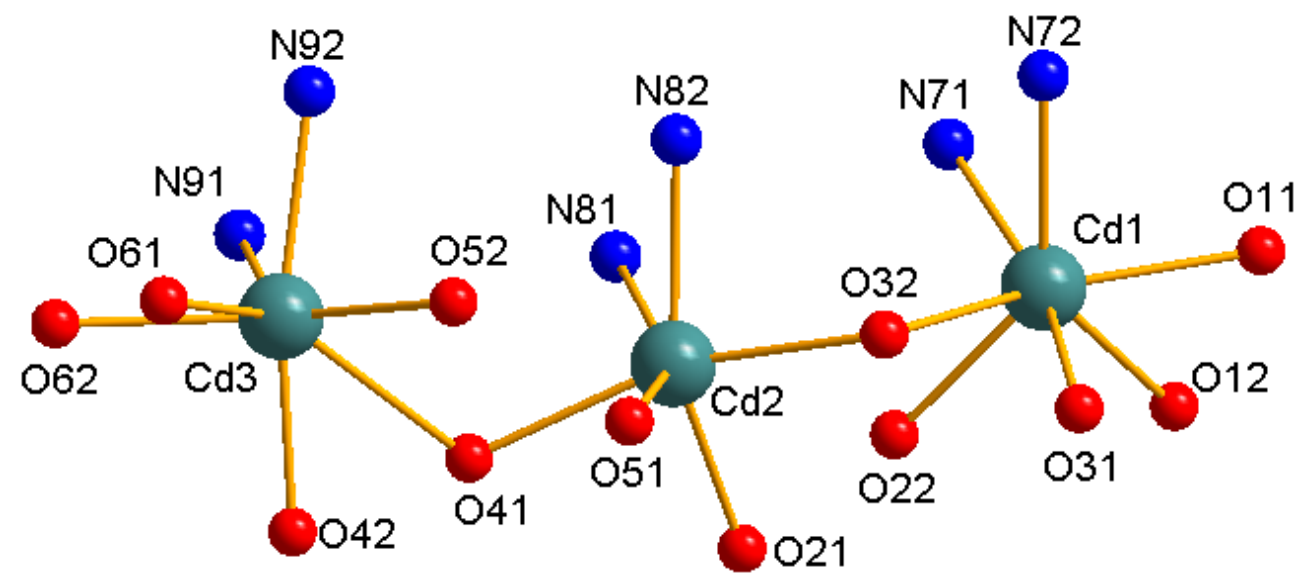

Figure 4. The coordination options of carboxylates in the Cd (II) complex.
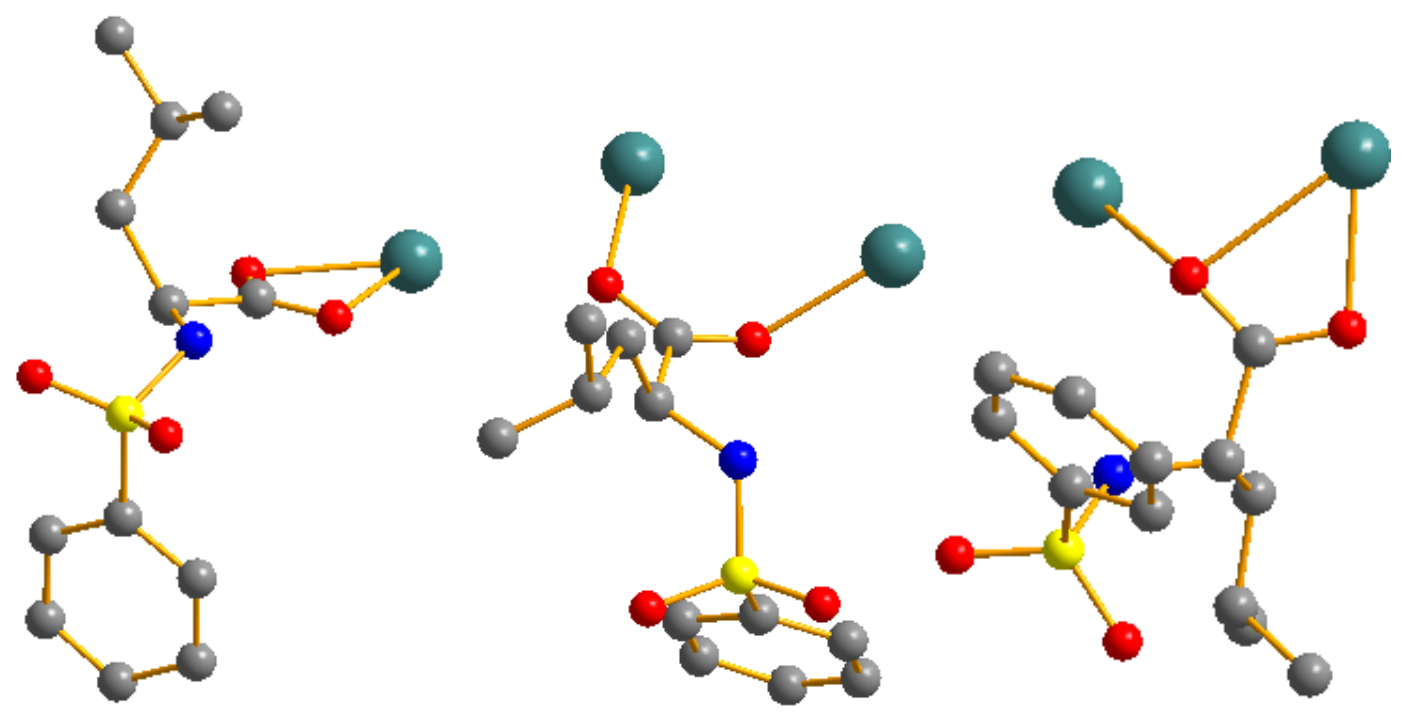

\subsection{Luminescent Properties}

Previous studies have shown that the Cd (II) complexes exhibit luminescent properties [11]. Hence, we investigated the luminescent properties of the $\mathrm{Cd}$ (II) complex in the solid-state and in $\mathrm{CH}_{3} \mathrm{OH}$ solution $\left(1.06 \times 10^{-5} \mathrm{~mol} \mathrm{~L}^{-1}\right)$ at room temperature. The emission spectra of the $\mathrm{Cd}$ (II) complex are shown in Figure 5. In the solid state, the Cd (II) complex displays strong luminescent emission bands at $442 \mathrm{~nm}$ when excited at $335 \mathrm{~nm}$. And in $\mathrm{CH}_{3} \mathrm{OH}$ solution, the $\mathrm{Cd}$ (II) complex displays strong luminescent emission bands at $457 \mathrm{~nm}$ when excited at $335 \mathrm{~nm}$. For excitation wavelengths between 280 and $420 \mathrm{~nm}$, there is no obvious emission observed for the $N$-benzenesulphonyl- $L$-leucine ligand. Compared with the emission maximum of the $\mathrm{Cd}$ (II) complex in methanol solution, the emission maximum of the Cd (II) complex in solid was blue shifted, which may be due to the quenching effect of the methanol solvent. 
Figure 5. The emission spectrum of the Cd (II) complex. The excitation and emission slit widths were $5 \mathrm{~nm}$.

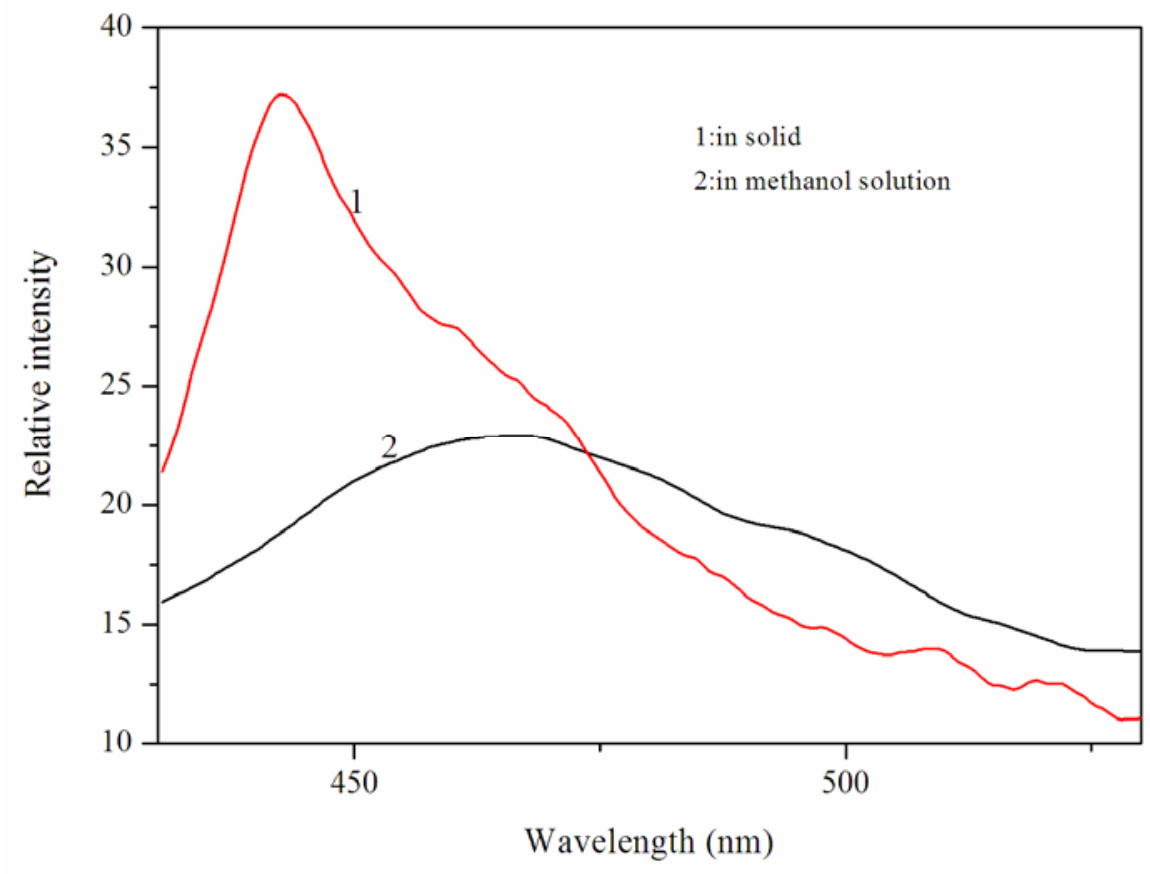

\section{Experimental Section}

\subsection{Materials and Methods}

The $N$-benzenesulphonyl- $L$-leucine ligand was prepared according to the method reported in the literature [5]. Other chemicals were of reagent grade and were used without further purification.

Carbon, hydrogen and nitrogen analyses were obtained using an Elementar Vario III EL elemental analyzer. Infrared spectra were recorded on a Nicolet AVATAR 360 FTIR spectrophotometer with $\mathrm{KBr}$ in the range of $400 \mathrm{~cm}^{-1}-4000 \mathrm{~cm}^{-1}$. Mass spectrum was performed on a VG ZAB-HS Fast-atom bombardment (FAB) instrument. Excitation and emission spectra were obtained on a PE LS-55 spectrometer at room temperature. X-ray diffraction data of the Cd (II) complex was collected on a Bruker smart CCD diffractometer.

\subsection{Synthesis of Cd (II) Complex}

A methanol solution of $0.5 \mathrm{~m} \mathrm{~mol}(0.1543 \mathrm{~g})$ cadmium nitrate tetrahydrate was added to a solution containing $1.0 \mathrm{~m} \mathrm{~mol}(0.2710 \mathrm{~g})$ of $N$-benzenesulphonyl- $L$-leucine and $1.0 \mathrm{~m} \mathrm{~mol}(0.04 \mathrm{~g})$ of sodium hydroxide in $10 \mathrm{~mL} \mathrm{CH} \mathrm{CH}_{3} \mathrm{OH}$. The mixture was continuously stirred for $2 \mathrm{~h}$ at refluxing temperature. The mixture was cooled at room temperature, and was collected by filtration. By evaporation in air at room temperature, a single crystal suitable for X-ray determination was obtained from methanol solution after 15 days. Elementary analysis: calcd for $\mathrm{C}_{102} \mathrm{H}_{120} \mathrm{Cd}_{3} \mathrm{~N}_{12} \mathrm{O}_{24} \mathrm{~S}_{6}$ : C, 50.42; H, 4.94; N, 6.92\%; found: $\mathrm{C}, 50.77 ; \mathrm{H}, 4.58 ; \mathrm{N}, 6.73 \%$. IR $v_{\max }\left(\mathrm{cm}^{-1}\right): v_{\text {as }}\left(\mathrm{COO}^{-}\right): 1,587 \mathrm{~cm}^{-1}, v_{\mathrm{s}}\left(\mathrm{COO}^{7}\right): 1402 \mathrm{~cm}^{-1}$, $v\left(-\mathrm{SO}_{2}-\mathrm{NH}-\right): 3,249 \mathrm{~cm}^{-1}, 1,320 \mathrm{~cm}^{-1}, 1,156 \mathrm{~cm}^{-1}, v(\mathrm{C}=\mathrm{N}): 1,552 \mathrm{~cm}^{-1}, v(\mathrm{Cd}-\mathrm{O}): 419 \mathrm{~cm}^{-1}$. 


\subsection{X-Ray Crystallography}

Single crystal X-ray diffraction data were collected on a Bruker smart CCD diffractometer at 153(2) K using graphite-monochromatic Mo $K \alpha$ radiation $(\lambda=0.71073 \AA)$. The structure was solved by the direct method and refined with full-matrix least-squares techniques using SHELXL-97 [12]. All non-hydrogen atoms were refined anisotropically, and all hydrogen atoms were put in calculated positions. Molecular graphics were drawn with the program package SHELXTL-97 crystallographic software package [13]. The main crystal data of the collection and refinement details of the Cd (II) complex are summarized in Table 1. Selected bond lengths and angles are listed in Table 2.

Table 1. Crystallographic data for the Cd (II) complex.

\begin{tabular}{ll}
\hline Crystallographic parameter & Crystallographic data \\
\hline Formula & $\mathrm{C}_{102} \mathrm{H}_{120} \mathrm{Cd}_{3} \mathrm{~N}_{12} \mathrm{O}_{24} \mathrm{~S}_{6}$ \\
Formula weight & 2427.66 \\
Crystal system & Orthorhombic \\
Space group & $P{ }_{1} 2_{1} 2_{1}$ \\
$a(\AA)$ & $16.877(3)$ \\
$b(\AA)$ & $22.875(5)$ \\
$c(\AA)$ & $29.495(6)$ \\
$\mathrm{Z}$ & 4 \\
$F(000)$ & 4992 \\
Temperature $(\mathrm{K})$ & $153(2)$ \\
$V\left(\AA^{3}\right)$ & $11387(4)$ \\
Calculated density $\left(\mu \mathrm{g} \cdot \mathrm{m}^{-3}\right)$ & 1.416 \\
Crystal size $\left.(\mathrm{mm})^{3}\right)$ & $0.24 \times 0.20 \times 0.12$ \\
$\mu\left(\mathrm{mm}{ }^{-1}\right)$ & 0.737 \\
$S$ & 1.060 \\
& $-20 \leq h \leq 20$, \\
Limiting indices & $-26 \leq k \leq 27$, \\
& $-35 \leq l \leq 34$ \\
Reflections collected/unique & $20023 / 17894$ \\
$R_{1}, w R_{2}[$ all data $]$ & $0.0452,0.1029$ \\
$R_{1}, w R_{2}[I>2 \sigma(I)]$ & $0.0390,0.0989$ \\
Largest diff.peak and hole $\left(\mathrm{e} \cdot \AA^{-3}\right)$ & $1.213-1.250$ \\
\hline
\end{tabular}


Table 2. Selected bond lengths $(\AA)$ and angles $\left(^{\circ}\right)$ for the Cd (II) complex.

\begin{tabular}{|c|c|c|c|}
\hline Bonds & Bond parameter & Bonds & Bond parameter \\
\hline $\mathrm{Cd} 1-\mathrm{O} 31$ & $2.241(3)$ & $\mathrm{Cd} 2-\mathrm{O} 41$ & $2.386(3)$ \\
\hline Cd1-N71 & $2.329(4)$ & $\mathrm{Cd} 2-\mathrm{O} 32$ & $2.408(3)$ \\
\hline $\mathrm{Cd} 1-\mathrm{O} 22$ & $2.331(3)$ & $\mathrm{Cd} 3-\mathrm{O} 42$ & $2.244(3)$ \\
\hline $\mathrm{Cd} 1-\mathrm{O} 11$ & $2.331(4)$ & $\mathrm{Cd} 3-\mathrm{O} 52$ & $2.310(3)$ \\
\hline Cd1-N72 & $2.366(4)$ & Cd3-N91 & $2.330(4)$ \\
\hline $\mathrm{Cd} 1-\mathrm{O} 12$ & $2.450(4)$ & $\mathrm{Cd} 3-\mathrm{N} 92$ & $2.347(5)$ \\
\hline $\mathrm{Cd} 2-\mathrm{O} 21$ & $2.253(3)$ & $\mathrm{Cd} 3-\mathrm{O} 62$ & $2.360(4)$ \\
\hline $\mathrm{Cd} 2-\mathrm{O} 51$ & $2.263(3)$ & $\mathrm{Cd} 3-\mathrm{O} 61$ & $2.420(4)$ \\
\hline $\mathrm{Cd} 2-\mathrm{N} 81$ & $2.335(4)$ & - & - \\
\hline $\mathrm{Cd} 2-\mathrm{N} 82$ & $2.341(4)$ & - & - \\
\hline O31-Cd1-N71 & $161.91(14)$ & O41-Cd2-N81 & $78.30(13)$ \\
\hline $\mathrm{O} 31-\mathrm{Cd} 1-\mathrm{O} 22$ & $92.09(14)$ & $\mathrm{O} 41-\mathrm{Cd} 2-\mathrm{N} 82$ & $116.50(13)$ \\
\hline N71-Cd1-O22 & $84.39(14)$ & $\mathrm{O} 21-\mathrm{Cd} 2-\mathrm{O} 32$ & $89.06(12)$ \\
\hline O31-Cd1-O11 & $94.74(16)$ & $\mathrm{O} 51-\mathrm{Cd} 2-\mathrm{O} 32$ & $81.05(12)$ \\
\hline N71-Cd1-O11 & $100.64(17)$ & N81-Cd2-O32 & $120.38(13)$ \\
\hline $\mathrm{O} 11-\mathrm{Cd} 1-\mathrm{O} 22$ & $133.05(13)$ & $\mathrm{O} 32-\mathrm{Cd} 2-\mathrm{N} 82$ & $78.95(13)$ \\
\hline O31-Cd1-N72 & $102.03(15)$ & $\mathrm{O} 32-\mathrm{Cd} 2-\mathrm{O} 41$ & $160.16(12)$ \\
\hline N71-Cd1-N72 & $70.04(15)$ & $\mathrm{O} 42-\mathrm{Cd} 3-\mathrm{O} 52$ & $94.83(13)$ \\
\hline N72-Cd1-O22 & $137.92(14)$ & N91-Cd3-O42 & $106.22(15)$ \\
\hline O11-Cd1-N72 & $85.50(15)$ & N91-Cd3-O52 & $133.77(15)$ \\
\hline O31-Cd1-O12 & $99.51(15)$ & O42-Cd3-N92 & $168.28(15)$ \\
\hline N71-Cd1-O12 & $97.17(16)$ & N92-Cd3-O52 & $80.53(14)$ \\
\hline $\mathrm{O} 12-\mathrm{Cd} 1-\mathrm{O} 22$ & $78.55(13)$ & N91-Cd3-N92 & $70.57(16)$ \\
\hline O11-Cd1-O12 & $54.50(14)$ & $\mathrm{O} 42-\mathrm{Cd} 3-\mathrm{O} 62$ & $91.90(15)$ \\
\hline N72-Cd1-O12 & $135.80(15)$ & $\mathrm{O} 52-\mathrm{Cd} 3-\mathrm{O} 62$ & $135.51(13)$ \\
\hline $\mathrm{O} 21-\mathrm{Cd} 2-\mathrm{O} 51$ & $103.84(12)$ & N91-Cd3-O62 & $85.27(16)$ \\
\hline $\mathrm{O} 21-\mathrm{Cd} 2-\mathrm{N} 81$ & $97.39(14)$ & O62-Cd3-N92 & $98.95(16)$ \\
\hline O51-Cd2-N81 & $150.20(14)$ & $\mathrm{O} 61-\mathrm{Cd} 3-\mathrm{O} 42$ & $100.38(13)$ \\
\hline $\mathrm{O} 21-\mathrm{Cd} 2-\mathrm{N} 82$ & $153.49(14)$ & O61-Cd3-O52 & $81.03(12)$ \\
\hline O51-Cd2-N82 & $97.58(13)$ & N91-Cd3-O61 & $132.21(14)$ \\
\hline N81-Cd2-N82 & $69.56(14)$ & O61-Cd3-N92 & $89.58(15)$ \\
\hline $\mathrm{O} 21-\mathrm{Cd} 2-\mathrm{O} 41$ & $81.37(11)$ & O62-Cd3-O61 & $54.52(13)$ \\
\hline $\mathrm{O} 51-\mathrm{Cd} 2-\mathrm{O} 41$ & $84.41(12)$ & - & - \\
\hline
\end{tabular}

\section{Conclusions}

In summary, by selecting the $\mathrm{Cd}$ (II) ion as a knot, and $N$-phenylsulfonyl- $L$-leucinato and 2,2-bipyridine as a building block, a new complex $\left[\mathrm{Cd}_{3}(\mathrm{~L})_{6}(2,2 \text {-bipyridine })_{3}\right]$ has been synthesized and structurally characterized. The complex comprises two seven-coordinated $\mathrm{Cd}$ (II) atoms, with a $\mathrm{N}_{2} \mathrm{O}_{5}$ distorted pengonal bipyramidal coordination environment and a six-coordinated Cd (II) atom, with a $\mathrm{N}_{2} \mathrm{O}_{4}$ distorted octahedral coordination environment. The molecules form a one dimensional chain structure by the interaction of bridged carboxylato groups and $\pi-\pi$ interaction of 2,2-bipyridine. The $\mathrm{Cd}$ (II) complex exhibited fluorescence in solid and in $\mathrm{CH}_{3} \mathrm{OH}$. Based on those results, a series of new Cd (II) complex could be designed and synthesized to optimize the luminescent properties. 


\section{Acknowledgments}

The authors would like to thank the National Natural Science Foundation of China (No. 21171132 and 20671073), the Promotive Research Fund for Excellent Young and Middle-aged Scientists of Shandong Province (2010BSA07004) and Science Foundation of Weifang University.

\section{Supplementary Material}

Crystallographic data for the structure reported in this paper has been deposited with the Cambridge Crystallographic Data Centre as supplementary publication No.CCDC 890837. Copy of the data can be obtained free of charge on application to CCDC, 12 Union Road, Cambridge CB2 1EZ, UK (Fax: +44-1223-336-033; E-Mail: deposit@ccdc.cam.ac.uk).

\section{References}

1. Tian, L.J.; Yang, H.J.; Zheng, X.L.; Ni, Z.H.; Yan, D.M.; Tu, L.L.; Jiang, J.Z. Synthesis, structural characterization and cytotoxic activity of diorganoyin (IV) complexes of N-(5-halosalicylidene)tryptophane. Appl. Organometal. Chem. 2009, 23, 24-31.

2. Kusrini, E.; Saleh, M.I.; Adnan, R.; Yulizar, Y.; Shiong, N.S.; Fun, H.K.; Abdullah, M.A.A.; Mamat, M.; Zaaba, N.K.; Majid, W.H.A. Structural, optical electrical properties of europium picrate tetraethylene glycol complex as emissive material for OLED. J. Luminesc. 2012, 132, 91-99.

3. Tang, Y.Z.; Zhou, M.; Yang, Y.M.; Wang, X.W.; Huang, S. Synthesis, crystal structure and characterization of olsalazine complex. J. Synth. Cryst. 2011, 40, 1083-1086.

4. Lu, W.G.; Jiang, L.; Feng, X.L.; Lu, T.B. Three 3D coordination polymers constructed by Cd(II) and $\mathrm{Zn}(\mathrm{II})$ with imidazole-4,5-dicarboxylate and 4,4'-bipyridyl building blocks. Cryst. Growth Des. 2006, 6, 564-571.

5. Tai, X.S.; Wei, N.; Wang, D.H. Synthesis, crystal structure and luminescent property of Mg (II) complex with $N$-benzenesulphonyl-L-leucine and 1,10-phenanthroline. Materials 2012, 5, $558-565$.

6. Wang, L.F.; Hu, Y.X.; Zhang, W.W.; Ren, X.M. Solvothermal synthesis, crystal structure and photoluminescence property of a coordination polymer based on 1,1'-ethynebenzene-3,3',5,5'tetracarboxylate. China J. Inorg. Chem. 2011, 27, 542-546.

7. Tai, X.S.; Feng, Y.M.; Wang, L.T.; Tan, M.Y. Synthesis, structure characterization and luminescent properties of ternary zinc acetate complex with 4-aminohippuric acid and 1,10-phenanthroline ligand. Polish J. Chem. 2009, 83, 1099-1104.

8. Nakamoto, K. Infrared and Ramen Spectra of Inorganic and Coordination Compounds, 3rd ed.; John Wiley and Sons: New York, NY, USA, 1978; Volume 1, pp. 359-368.

9. Liu, D.; Li, N.Y. Poly[di- $\mu$-1,2-bis(pyridine-4-yl)-ethene- $N: N^{\prime}$-tetrakis(4-iodobenzoato- $\left.O, O^{\prime}\right)$ dicadmium. Acta Cryst. 2012, C68, m21-m23.

10. Jian, F.F.; Xiao, H.L.; Sun, P.P.; Zhao, P.S. Crystal structure and characterization of the dinuclear $\mathrm{Cd}(\mathrm{II})$ complex $\left[\mathrm{Cd}\left(\mathrm{H}_{2} \mathrm{O}\right)_{2}\left(\mathrm{o}-\mathrm{HOC}_{6} \mathrm{H}_{4} \mathrm{COO}\right)_{2}\right]_{2}$. Molecules 2004, 9, 876-882. 
11. Tao, J.; Yin, X.; Wei, Z.B.; Huang, R.B.; Zheng, L.S. Hydrothermal syntheses, crystal structures and photoluminescent properties of three metal-cluster based coordination polymers containing mixed organic ligands. Eur. J. Inorg. Chem. 2004, 1, 125-133.

12. Sheldrick, G.M. SHELXL-97, Program for Crystal Structure Solution; University of Göttingen: Göttingen, Germany, 1997.

13. Sheldrick, G.M. SHELXTL-97, Program for Crystal Structure Refinement; University of Göttingen: Göttingen, Germany, 1997.

(C) 2012 by the authors; licensee MDPI, Basel, Switzerland. This article is an open access article distributed under the terms and conditions of the Creative Commons Attribution license (http://creativecommons.org/licenses/by/3.0/). 